\title{
Erratum to: Xi Jinping's “New Normal”: Quo Vadis?
}

\section{Lowell Dittmer ${ }^{1}$}

Published online: 24 June 2017

(C) Journal of Chinese Political Science/Association of Chinese Political Studies 2017

\section{Erratum to: J OF CHIN POLIT SCI \\ DOI: 10.1007/s11366-017-9489-4}

Unfortunately, the original article contained an incorrect title due to a mistake made at the Publisher's end. We apologize for this mishap.

The original article has been updated with the correct title.

The online version of the original article can be found at http://dx.doi.org/10.1007/s11366-017-9489-4

Lowell Dittmer

dittmer@berkeley.edu

1 University of California Berkeley, Berkeley, CA, USA 